УДК 666.295.7:666.52+666.642.1

DOI: $10.15587 / 2313-8416.2014 .28684$

\title{
ЗНЕПРОЗОРЕНІ НЕФРИТТОВАНІ ПОЛИВИ ДЛЯ ФАЯНСУ ТА НИЗЬКОТЕМПЕРАТУРНОГО ФАРФОРУ
}

\author{
() О. Ю. Федоренко, М. І. Рищенко, К. Б. Дайнеко, Ю. В. Пермяков
}

Представлені результати досліджень впливу складу оксидних композицій на властивості полив 3 температурою формування 1150-1200 ${ }^{\circ} \mathrm{C}$. Встановлені математичні залежності блиску, білизни та термостійкості покриттів від вмісту скло утворюючої, модифікуючої та заглушуючої складових. Розроблено склади нефритованих знепрозорених полив, визначено властивості та особливості структури та фазового складу покриттів, отриманих з їх використанням.

Ключові слова: нефритовані поливи, непрозорість, глушники, модифікатори, склоутворювачі, блиск, білизна, термостійкість.

The study results of the oxide composition influence on the glaze properties with temperature formation 1150 $1200{ }^{\circ} \mathrm{C}$ are presented. The mathematical dependence of coating gloss, whiteness, thermal stability of coatings on the content of glass-forming, modifying and mufflers components are fitted. The composition of unfritted opaque glazes is developed and the properties and structure and phase composition characteristics of coatings, obtained from using them are defined.

Keywords: unfritted glazes, opaqueness, mufflers, modifiers, glass formers, gloss, whiteness, thermal stability.

\section{1. Вступ}

Поливи, які використовують при виготовленні виробів $з$ фаянсу, м'якого і низькотемпературного фарфору, рідше 3 майоліки, характеризуються відносно високою температурою формування, що дозволяє розглядати можливість використання в якості технологічної суміші композицій сировинних матеріалів. Це дозволить виключити енергоємну операцію фритування, яка полягає у попередньому плавленні шихти при 1300-1350 ${ }^{\circ} \mathrm{C}$ та відкриває можливості економії природного палива. Основною умовою реалізації такого підходу є грунтовний вибір сировинної композиції, яка має складатися 3 виключно нерозчинних у воді компонентів та забезпечувати формування знепрозореного покриття в заданих температурно-часових умовах випалу виробів. При цьому слід також враховувати, що при термообробці нефритованої поливи процеси розкладання сировини, склоутворення і кристалізації, а також поліморфні перетворення алотропних сполук відбуваються одночасно із формуванням керамічної основи та її взаємодію з розплавом поливи.

\section{2. Постановка проблеми}

Виключення фритування при виготовленні полив, на наш погляд, $\epsilon$ вагомим резервом енергозаощадження в технології фаянсових та фарфорових виробів, випал яких здійснюється однократно при температурі $1150 \div 1200{ }^{\circ} \mathrm{C}$. Для підвищення якості господарчо-побутових та санітарно-технічних фаянсових та фарфорових виробів необхідним $\epsilon$ створення знепрозорених нефритованих полив з високими показниками блиску та білизни. Тому розробка складів нефритованих полив, здатних утворювати високоякісне покриття при в зазначеній температурі $\epsilon$ необхідною. При цьому поливи не повинні містити гостродефіцитних матеріалів, характеризуватись обмеженим вмістом високовартісних компонентів та повним виключенням токсичних складових.

\section{3. Літературний огляд}

Оскільки покриття по кераміці, що отримують на основі нефритованих полив $є$ по суті тонким скловидним шаром, то у відношенні до нього правомірним $\epsilon$ використання відомих положень скловидного стану. Як відомо, формування якісного поливного покриття визначається процесом розтікання поливи по поверхні матеріалу, який залежить, перш за все, від властивостей поливи - іiі плавкості, в'язкості, поверхневого натягу та змочувальної здатності розплаву, а також від відповідності температурних коефіцієнтів лінійного розширення поливного покриття і керамічної основи.

Для отримання рівної i гладкої поверхні поливи ії плавкість (температура переходу з твердого стану до розплавленого) повинна відповідати температурі спікання кераміки, яка, у свою чергу залежить від кількості, складу і властивостей рідкої фази в керамічному матеріалі. Як відомо, для формування бездефектного покриття в'язкість розплаву поливи при термообробці виробів має знаходитись в певних межах $\left(\eta=10^{2,5} \div 10^{3,5}\right.$ Па·с). В іншому випадку спостерігається стікання малов'язкого рухливого розплаву 3 виробів, надмірне всмоктування розплаву порами, що викликає появу дефектів глазурного покриття, або ж в разі занадто високої в'язкості розплаву, спостерігається утворення пухирів. Дослідження відомих спеціалістів в галузі полив та покриттів по кераміці [1-3] вказують на те, що при підвищені поверхневого натягу поверхня поливи стає рівною та гладенькою, зменшується кількість наколів. 3 іншого боку при надмірному збільшенні поверхневого натягу (понад 0,35 Н/м) уповільнюється заплавлення кратерів та тріщин, які можуть утворюватись в покритті при термообробці. Окрім цього зависокий 
поверхневий натяг негативно позначається на змочувальній здатності поливи, внаслідок чого виникає дефект поливи «збірка».

Знепрозорення полив зазвичай досягається за рахунок введення глушників (твердофазних сполук), при виборі яких слід враховувати їх ефективність, вартість та екологічність. Як глушники найчастіше використовують оксиди елементів четвертої і п'ятої груп Періодичної системи (як, наприклад, $\mathrm{ZrO}_{2}, \mathrm{ZnO}$, $\mathrm{SnO}, \mathrm{TiO}_{2}, \mathrm{Sb}_{2} \mathrm{O}_{3}$ тощо), кожен 3 яких має свої переваги та недоліки. Ступінь знепрозорення підвищується із збільшенням різниці коефіцієнтів заломлення диспергованих часток глушника i скловидної фази поливи, для якої $\mathrm{N}_{\mathrm{p}}=1,5 \div 1,6$. При цьому більший ефект досягається у тому випадку якщо вони розчиняються в розплаві поливи, що утворюється при нагріванні та кристалізуються при охолодженні матеріалу. В більшій мірі такий механізм реалізується при випалі фритованих полив, але при формуванні нефритованих полив глушник також частково розчиняється та кристалізується 3 розплаву у вигляді високодисперсних часточок $(0,1-$ 0,5 мкм), що підвищує ефект знепрозорення, який значно підсилюється завдяки утворенню додаткових меж розподілу у вигляді ліквацій них неоднорідностей та численних дрібних газових включень. Важливими факторами, які визначають умови отримання знепрозорених полив є: оптимальні режими випалу та наявність передкристалізаційної ліквації склофази. Останній фактор у великій мірі обумовлений присутністю оксидів-модифікаторів, які деполімеризують сітку скла та створюють умови для ліквації і наступної кристалізації [4].

Найбільш ефективним глушником для полив за даними [5] є діоксид стануму.

Як відомо, станумвмісні поливи характеризуються унікальними термомеханічними властивостями завдяки кристалізації каситериту, як ефективного глушника 3 показником заломлення $\left(\mathrm{N}_{\mathrm{p}}=2,1\right)$. В присутності лужноземельних оксидів утворення каситериту інтенсифікується. Дослідження потрійних станумвмісних систем [6, 7], що містять лужноземельні оксиди кальцію, магнію, цинку, барію, дозволило встановити, що найбільш низькотемпературні евтектики розташовуються поблизу ребер $\mathrm{SnO}_{2}-\mathrm{RO}$. Оскільки в даному випадку температури евтектик $\epsilon$ вищими за температуру випалу фарфорових виробів, для отримання нефритованих станумвмісних полив із температурою формування $1150 \div 1200{ }^{\circ} \mathrm{C}$ необхідним є введення до складу композицій легкоплавких лужних оксидів. Враховуючи той факт, що в присутності лужних оксидів відбувається активне розчинення каситериту, вміст оксидів $\mathrm{CaO}, \mathrm{ZnO}, \mathrm{BaO}$ у складі полив має бути достатнім для стабілізації цієї кристалічної фази. Тому для розробки оксидних композицій, які забезпечують формування знепрозорених покрить 3 температурою формування $1150 \div 1200{ }^{\circ} \mathrm{C}$ обрана базова система оксидів $\mathrm{R}_{2} \mathrm{O}-\mathrm{RO}-\mathrm{Al}_{2} \mathrm{O}_{3}-\mathrm{SiO}_{2}$ (де $\mathrm{R}_{2} \mathrm{O}=\mathrm{Na}_{2} \mathrm{O}, \mathrm{K}_{2} \mathrm{O} ; \mathrm{RO}=\mathrm{CaO}, \mathrm{BaO}, \mathrm{ZnO}$ ).
4. Розробка та оптимізація складу нефритова них знепрозорених полив

Вищевикладене дозволило сформулювати основні принципи отримання знепрозорених нефритованих полив для фаянсу та низькотемпературного фарфору:

- сумарна кількість лужних оксидів обмежується 6 мас. \%; при одночасній присутності двох лужних оксидів у складі поливи має переважати $\mathrm{K}_{2} \mathrm{O}$;

- для зменшення температури формування покриття вміст $\mathrm{SiO}_{2}$ обмежується 60 мас. \%, а кількість $\mathrm{Al}_{2} \mathrm{O}_{3} \leq 12$ мас. \%; оксиди $\mathrm{Al}_{2} \mathrm{O}_{3} \mathrm{i} \mathrm{SiO}_{2}$ мають знаходитись у співвідношенні від $1: 4,0$ до 1 : 6,5

- як глушники слід використовувати сполуки 3 високим показником заломлення у порівнянні із середнім показником заломлення склофази $(1,55)$;

- решта компонентів має бути представлена оксидами-модифікаторами $(\mathrm{CaO}, \mathrm{BaO}, \mathrm{ZnO})$, які позитивно впливають на плавкість та якість розливу поливи.

- введення оксидів до складу нефритованих полив базової системи має відбуватись 3 використанням сировинних матеріалів, нерозчинних у воді.

3 використанням цих положень шляхом прогнозування структурних характеристик склокомпозицій, розрахунків температури їх формування та технологічних властивостей для отримання нефритованих знепрозорених полив визначені наступна область складів склокомпозицій в системі $\mathrm{R}_{2} \mathrm{O}-\mathrm{RO}$ $\mathrm{Al}_{2} \mathrm{O}_{3}-\mathrm{SiO}_{2}-\mathrm{SnO}_{2}$ (де $\mathrm{R}_{2} \mathrm{O}-\mathrm{Na}_{2} \mathrm{O}, \mathrm{K}_{2} \mathrm{O}$; $\mathrm{RO}-\mathrm{CaO}, \mathrm{ZnO}$, $\mathrm{BaO}$ ), мас. \%: $\mathrm{Na}_{2} \mathrm{O}-1,5 \div 3 ; \mathrm{K}_{2} \mathrm{O}-1,5 \div 3 ; \mathrm{Al}_{2} \mathrm{O}_{3}-9 \div 16$; $\mathrm{BaO}-5 \div 8 ; \quad \mathrm{ZnO}-5 \div 8 ; \quad \mathrm{CaO}-5 \div 8 ; \quad \mathrm{SnO}_{2}-8 \div 15$; $\mathrm{SiO}_{2}-55 \div 65$. Композиції, які належать до цієї області відрізняються температурою розливу $\left(1150 \div 1200{ }^{\circ} \mathrm{C}\right)$, високою кристалізаційною здатністю, найнижчими показниками в'язкості $\left(10^{2,4 \div 2,5}\right.$ Па·с) та поверхневого натягу $(321 \div 324 \mathrm{H} / \mathrm{Mm})$ розплаву.

Оскільки об’єм експериментів залежить від кількості та форми представлення інформації про об'єкт досліджень, для оптимізації складу нефритованих полив залучався метод симплексгратчастого планування 3 використанням планів Шефе неповного 3-го порядку, суть якого полягає в отриманні аналітичної залежності будь-якої властивості суміші від іiі складу 3 використанням спеціальних алгоритмів. У даному дослідженні застосовано симплекс спеціальної кубічної моделі неповного третього порядку, в якому факторами $X_{i}$ $(i=1 . . .3)$ служили кількісний вміст скло-утворюючої, модифікуючої та заглушуючої складових поливи. Як відгуки розглядались такі властивості покриттів як білизна, блиск та термічна стійкість. Як склоутворююча складова розглядалась сума оксидів $\mathrm{SiO}_{2}$ та $\mathrm{Al}_{2} \mathrm{O}_{3}$; роль модифікаторів виконували лужноземельні оксиди $\mathrm{CaO}, \mathrm{BaO}$ та $\mathrm{ZnO}$, а також лужні оксиди $\mathrm{K}_{2} \mathrm{O}, \mathrm{Na}_{2} \mathrm{O}$; заглушуюча складова полив представлена оксидом $\mathrm{SnO}_{2}$. Виходячи 3 вимог до складу нефритованих полив та результатів прогнозних розрахунків властивостей оксидних 
композицій, встановлені наступні межі варіювання вказаних складових: склоутворювачі $\left(\mathrm{SiO}_{2}+\mathrm{Al}_{2} \mathrm{O}_{3}\right)-$ $65 \div 75$ мас.\%; модифікатори $\left(\mathrm{CaO}+\mathrm{BaO}+\mathrm{ZnO}+\mathrm{K}_{2} \mathrm{O}+\right.$ $\left.+\mathrm{Na}_{2} \mathrm{O}\right)-20 \div 30$ мас. $\%$; заглушувач $\mathrm{SnO}_{2}-$ $3 \div 8$ мac. $\%$.

Для приготування сировинних сумішей використовували як природну сировину (пісок новоселівський, ПШМ лозуватський, каолін просянівський, крейду білгородську), так і технічні продукти (цинкові білила, карбонат барію та оксид олова).

Інформація щодо впливу хімічного складу полив на їх властивості, яка представлена у вигляді залежностей, що характеризують взаємозв'язок “склад - властивість”, дозволяє здійснювати оптимізацію складу поливи за певними критеріальними ознаками 3 використанням прикладних комп'ютерних програм. В результаті статистичної обробки експериментальних даних 3 використанням програмного пакету "STATISTICA" визначено математичні залежності, які описують вплив склоутворюючої, модифікуючої та заглушуючої складових нефритованих полив на показники білизни, блиску та термостійкості покриттів, отриманих при 1150 i $1200{ }^{\circ} \mathrm{C}$ :

$$
\begin{aligned}
& \text { Білизна }_{1150^{\circ} \mathrm{C}}=87,51 x+87,74 y+89,74 z-0,86 x y+ \\
& +0,34 x z+2,72 y z+25,26 x y z . \\
& \text { Білизна }_{1200^{\circ} \mathrm{C}}=87,48 x+87,2 y+89,6 z-8,16 x y+ \\
& +3,12 x z+5,8 y z-7,32 x y z . \\
& \quad \text { Блиск } \kappa_{1150^{\circ} \mathrm{C}}=32,5 x+62 y+37 z-7 x y+ \\
& \quad+32 x z+48 y z-222,9 x y z . \\
& \quad \text { Блиск } \kappa_{1200^{\circ} \mathrm{C}}=41 x+48 y+40 z-6 x y+ \\
& \quad+6 x z+8 y z-294 x y z .
\end{aligned}
$$

Термостійкість ${ }_{1500^{\circ} \mathrm{C}}=150 x+225 y+225 z+50 x y-$ $-5 x z-100 y z-975 x y z$.

$$
\begin{aligned}
& \text { Термостійкість }{ }_{1200^{\circ} \mathrm{C}}=150 x+200 y+225 z+100 x y+ \\
& +50 x z-50 y z-750 x y z .
\end{aligned}
$$

Рівняння регресії (1)-(6) $є$ адекватними, оскільки відхилення розрахункових показників властивостей від експериментальних даних становила від $1 \div 4 \%$. Графічна інтерпретація отриманих залежностей представлена на рис. 1.
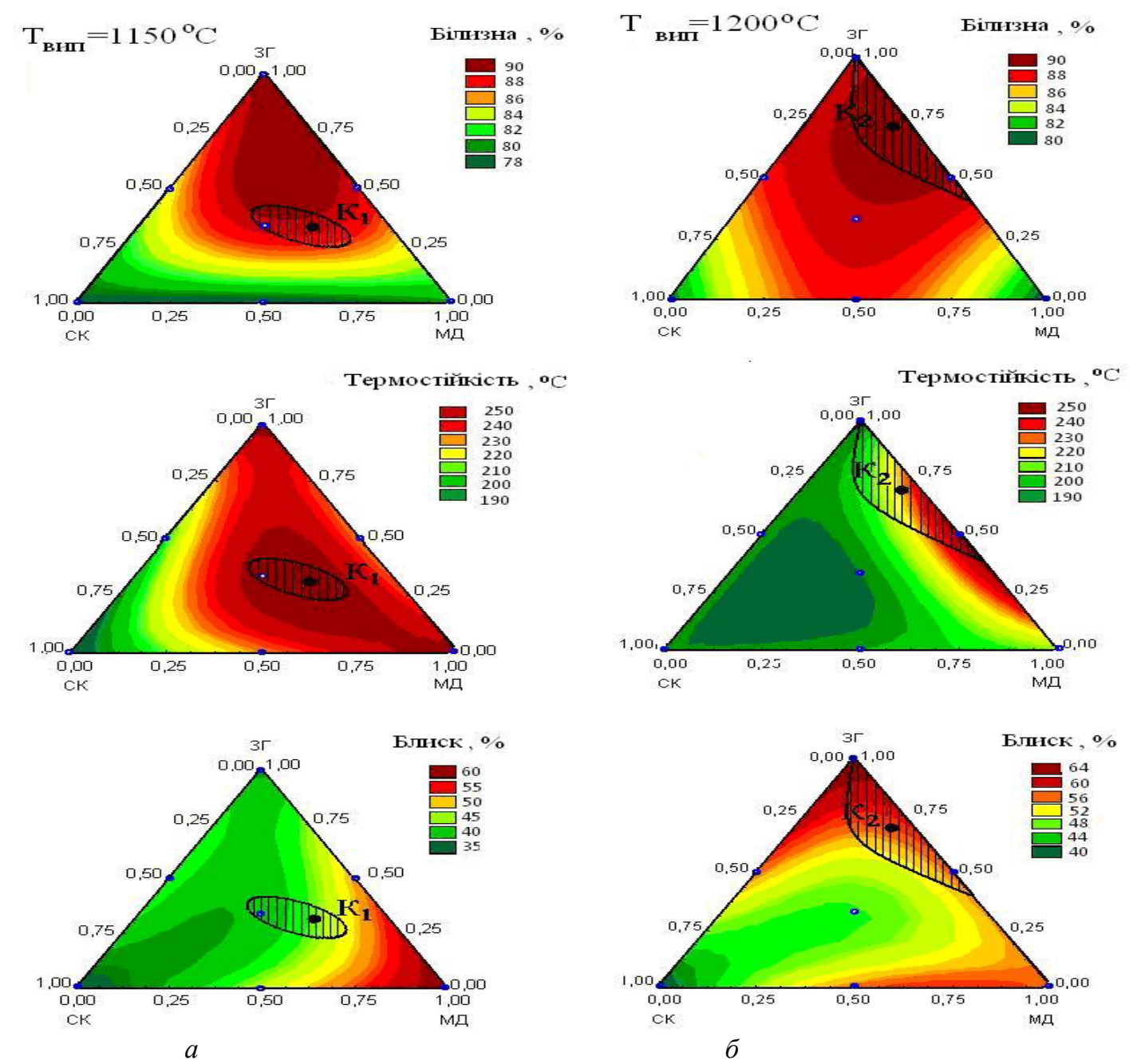

Рис. 1. Діаграми «склад-властивість» для полив, отриманих при температурі випалу: $a-1150{ }^{\circ} \mathrm{C}$; $\sigma-1200^{\circ} \mathrm{C}$ 
Максимальні показники білизни покриттів досягаються при збільшенні вмісту заглушуючої складової поливи, що є логічним, оскільки при цьому підвищується імовірність утворення кристалічних фаз із високими показниками заломлення, таких як, наприклад, каситерит $\left(\mathrm{SnO}_{2}\right)$ та ганіт $\left(\mathrm{ZnAl}_{2} \mathrm{O}_{4}\right)$.

Максимальні показники блиску поверхні покрить спостерігаються при співвідношенні модифiкатор : заглушувач : склоутворювач $=25: 10: 65$, а поливи зі співвідношенням складових 22:8:70 характеризуються шовковистою матовістю. Зростання термостійкості покриттів до $250{ }^{\circ} \mathrm{C}$ і вище у випадку відбувається у випадку, якщо співвідношення модифікатор : заглушувач : склоутворювач знаходиться в межах $23 \div 27: 7 \div 9 \wedge 67 \div 71$. На основі комплексного аналізу отриманих даних встановлена оптимальна область складів нефритованих знепрозорених полив, які дозволяють отримати якісні покриття 3 властивостями, що задовольняють вимогам стандарту [8]: термостійкість $240 \div 250{ }^{\circ} \mathrm{C}$; блиск $63 \div 65 \%$, білизна $87 \div 89 \%$.

3 використанням РФА визначено фазовий склад покриттів, основні фази яких представлені каситеритом $(d=0,2384 ; 0,2666 ; 0,3384$ нм $)$, та рентгеноаморфною склофазою (рис. 2, a). Як супутню кристалічну фазу ідентифіковано ганіт $(d=0,1857 ; \quad 0,0227 ; \quad 0,2446 ; \quad 0,2873 \quad$ нм $) . \quad$ На мікрофотознімку покриття (рис. 2, б) чітко видні добре оформлені кристали каситериту у вигляді пірамід та біпірамід розміром від 1 до 2,5 мкм, які рівномірно розподілені в склофазі покриття.

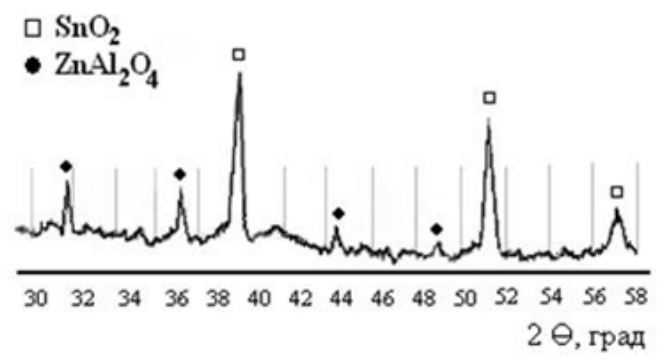

$a$

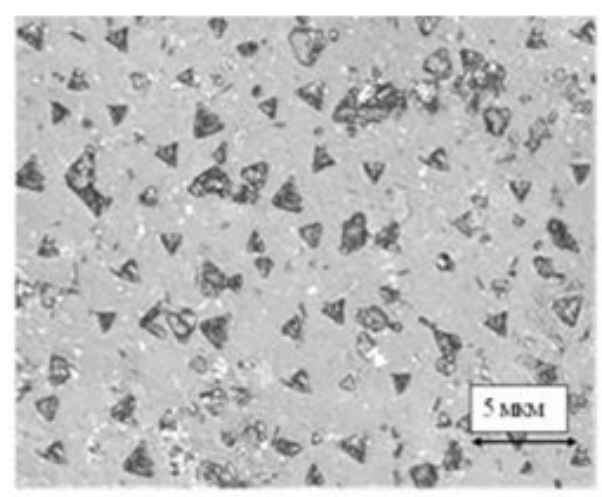

6

Рис. 2. Фазовий склад та структура покриття $\mathrm{H} 3-\mathrm{Sn}$, отриманого при $1150^{\circ} \mathrm{C}: a$ - рентгенограма; $\sigma$ - мікрофотографія
3 підвищенням температури випалу з $1150{ }^{\circ} \mathrm{C}$ до $\quad 1200^{\circ} \mathrm{C}$ відбувається збільшення площі рентгеноаморфної фази, яка характеризує кількість склофази. При товщині шару поливи 136 $\div 140$ мкм покриття характеризується високою об'ємною тонкодисперсною кристалізацією та хорошим зчепленням із керамічною основою. Завдяки високій знепрозореності розроблені покриття підвищують естетико-споживчі властивості виробів 3 фаянсу та низькотемпературного фарфору.

\section{5. Апробація результатів}

Розроблені склади полив 3 температурою формування $1150 \div 1200{ }^{\circ} \mathrm{C}$ дозволили отримати якісні матові (блиск $45 \%$ ), та глянцеві (блиск $64 \%$ ) покриття 3 високою термостійкістю $\left(250 \quad{ }^{\circ} \mathrm{C}\right)$ i білизною $(88 \div 90$ \%). Лабораторно-промислові випробування нефритованих знепрозорених полив в умовах ТОВ «Баранівський фарфоровий завод» показали ефективність використання розробок при однократному випалі фаянсових та фарфорових виробів господарчо-побутового призначення.

\section{6. Висновки}

В результаті проведених досліджень встановлені залежності основних властивостей, що обумовлюють якість покриттів, формування яких відбувається в умовах тривалого випалу при $1150 \div 1200{ }^{\circ} \mathrm{C}$, від хімічного складу полив. Визначені оптимальні співвідношення оксидів, що виконують різні функції (склоутворювачів, модифікаторів, глушників) для отримання матових та глянцевих покриттів, знепрозорення яких відбувається за рахунок кристалізації каситериту та ганіту. Розроблено склади знепрозорених нефритованих полив для фаянсу та низькотемпературного фарфору та визначені характерні особливості структуро- та фазоутворення поливи оптимального складу.

\section{Література}

1. Носова, 3. А. Циркониевые глазури [Текст] / 3. А. Носова. - М: Стройиздат, 1973. - 192 с.

2. Лисачук, Г. В. Стеклокристаллические покрытия по керамике [Текст]: монография / Г. В. Лисачук, М. И. Рыщенко, Л. А. Белостоцкая и др.; под ред. Г. В. Лисачука. - Х: НТУ «ХПИ», 2008. - 480 с.

3. Левицкий, И. А. Легкоплавкие глазури для облицовочной и бытовой керамики [Текст]: монография / И. А. Левицкий. - Минск: БГТУ, 1999. - 396 с.

4. Бобкова, Н. М. Бесщелочные ситаллы и стеклокристаллические материалы [Текст]: монография / Н. М. Бобкова, Л. М. Силич. - Минск: Наука и техника, 1992. $-277 \mathrm{c}$.

5. Блюмен, Л. М. Глазури [Текст]: монография / Л. М. Блюмен. - М.: Промстройиздат, 1954. - 172 с.

6. Минералы. Диаграммы фазовых равновесий. Вып. 1. [Текст]: справ. / под ред. Ф. В. Чухрова. - М.: Наука, 1974. - 514 с.

7. Lisachuk, G. Theoretical background of alkaline-free tin content coatings on ceramic in the system $\mathrm{RO}-\mathrm{SnO}_{2}-$ $\mathrm{Al}_{2} \mathrm{O}_{3}-\mathrm{SiO}_{2}$ [Text] / G. Lisachuk, O. Fedorenko, O. Pitak, L. //Chemistry \& Chemical technology. - 2013. - Vol. 7, Issue 3. - P. 351-354.

8. Изделия фарфоровые. Технические условия : ГОСТ 28390-89 [Текст] / Введен 01-01-91. - М.: 
Межгосударственный совет по стандартизации, метрологии и сертификации, 1989. - 13 с.

\section{References}

1. Nosova, Z. A. (1973). Zirconium glazes. Leningrad, USSR: Stroyizdate, 192.

2. Lisachuk, G. V., Ryshchenko, M. I., Belostotskaya, L. A. et al. (2008). Glass-ceramic coatings. Kharkov, Ukraine: NTU "KPI", 480.

3. Levitsky, I. A. (1999). Fusible glazes for tiles and household ceramics. Minsk, Belarus: Belarusian State Technological University, 396.
4. Bobkova, N. M., Silich, L. M. (1992) Alkali-free glass-ceramics and glass-crystalline materials. Minsk, Belarus: Science and Technology, 277.

5. Bloemen, L. M. (1954) Glazes. Moscow, USSR: Promstroyizdat, 172.

6. Minerals. Equilibrium phase diagram: a handbook. Issue 1. (1974). Moscow, USSR: Science, 514.

7. Lisachuk, G., Fedorenko, O., Pitak, O. et al. (2013). Theoretical background of alkaline-free tin content coatings on ceramic in the system $\mathrm{RO}-\mathrm{SnO}_{2}-\mathrm{Al}_{2} \mathrm{O}_{3}-\mathrm{SiO}_{2}$. Chemistry \& Chemical technology, 7 (3), 351-354.

8 Porcelain articles. Specifications GOST 28390-89. (1989). Moscow, USSR.: Interstate Council for Standardization, Metrology and certification, 13.

Дата надходження рукопису 10.10.2014

Федоренко Олена Юріївна, доктор технічних наук, профессор, кафедра технологи кераміки, вогнетривів, скла та емалей, Національний технічний університет «Харківський політехнічний інститут», вул. Фрунзе, 21, м. Харків, Україна, 61002

E-mail: fedorenko_e@ukr.net

Рищенко Михайло Іванович, доктор технічних наук, профессор, кафедра технологи кераміки, вогнетривів, скла та емалей, Національний технічний університет «Харківський політехнічний інститут», вул. Фрунзе, 21, м. Харків, Україна, 61002

Дайнеко Катерина Борисівна, аспірант, кафедра технологи кераміки, вогнетривів, скла та емалей, Національний технічний університет «Харківський політехнічний інститут», вул. Фрунзе, 21, м. Харків, Україна, 61002

E-mail: catherine@i.ua

Пермяков Юрій В'ячеславович, доцент, кафедра технологи кераміки, вогнетривів, скла та емалей, Національний технічний університет «Харківський політехнічний інститут», вул. Фрунзе, 21, м. Харків, Україна, 61002

УДК 681.3:655

DOI: $10.15587 / 2313-8416.2014 .28817$

\section{ИССЛЕДОВАНИЕ ЗАДАЧИ АВТОМАТИЗАЦИИ ПОДГОТОВКИ К ПЕЧАТИ СТАРИННЫХ ИЗДАНИЙ}

\section{(C) И. В. Тришина, А. В. Бизюк}

В данной работе исследуется процесс автоматизации подготовки к печати старинных изданий на примере дореволюиионной книги с иелью усовершенствовать и ускорить процесс. Приведен и подробно рассмотрен этап, занимающий больше всего времени в данном процессе. Предложен метод частичной автоматизации данного этапа.

Ключевые слова: оптическое распознавание символов, текстовая информаџия, коррекиия, макрос.

This paper describes the old publications automation process based on the example of a pre-revolutionary book with the purpose of improving and speeding up this process. The step that takes most of the process time is shown and clarified. A partial automation method for this step is proposed.

Keywords: optical character recognition, text information, correction, macro.

\section{1. Введение}

Несмотря на развитие электронных технологий, одним из основных способов получения информации все еще являются книги.

Производство книжной продукции является очень сложным, многоэтапным процессом и важным этапом определяющим изготовление книжной изделий является разработка технологии ее изготовления.

Повышена необходимость оцифровки старин- ных и ветхих книг, которые находятся на грани исчезновения, а так же их переиздание [1].

Переиздание - каждая новая публикация, отличающаяся от предыдущих минимум номером типографского заказа или же изменениями, как содержания (основного текста), так и оформления [2].

Не маловажной проблемой является адаптация дореволюционной орфографии. Часть книг переиздается с адаптацией со старого правописания на новое, для восприятия информации более широким кругом 